\title{
Study on the Carbon Emission Reduction Performance of Resource Tax Reform: Based on the Perspective of Substitution of Factors of Production
}

\author{
Jing Chen \\ School of Economics, Jinan University, Guangzhou, China \\ Email: 1006609313@qq.com
}

How to cite this paper: Chen, J. (2017) Study on the Carbon Emission Reduction Performance of Resource Tax Reform: Based on the Perspective of Substitution of Factors of Production. Open Journal of Business and Management, 5, 182-193. http://dx.doi.org/10.4236/ojbm.2017.51017

Received: January 5, 2017

Accepted: January 21, 2017

Published: January 24, 2017

Copyright $\odot 2017$ by author and Scientific Research Publishing Inc. This work is licensed under the Creative Commons Attribution International License (CC BY 4.0).

http://creativecommons.org/licenses/by/4.0/

\section{Open Access}

\begin{abstract}
Resource tax is an important means to regulate energy consumption. Recent years, in order to alleviate the structural contradiction of supply and demand of energy in our country, the resource tax rate was adjusted repeatedly. This paper introduced energy factor into the production function model, using 2003-2011 industry panel data to estimate the degree of influence of the adjustment of the resource tax rate to the factor input structure and the production efficiency of resource consuming industries. Through empirical research, the following conclusions can be drawn: 1) The increasing resource tax accounted for the proportion of the total tax will prompt the resource consumption industries for re-allocation of production factors and capital and human resources elements will replace energy factor. This is conducive to optimize the structure of production factors, so as to promote the industry to improve production efficiency. 2) In high energy consumption industry, the substitution effect of capital factor on energy factor is more significant than the substitution effect of labor factor on energy factor; however, in low energy consumption industry, the substitution effect of labor on energy factor is more significant than capital elements' substitution effect. 3) Compared with non-resource production industry, the impact of increasing the rate of resource tax on resource production industry mainly occurs as the alternative of labor actor for energy actor, and the substitution effect of capital is not significant.
\end{abstract}

\section{Keywords}

Resource Tax, Carbon Emission, Energy Consumption, Factor Substitution, Production Efficiency

\section{Introduction}

Global warming, as the most important environmental problem that human society has 
faced so far, is also the survival challenge that mankind faces in the twenty-first century. As the mainstream scientific community's concern about the warming effect of carbon emissions has stimulated global political response to global warming, carbon emissions have also evolved from scientific issues to economic and political issues. In this context, in 1997, the Kyoto Protocol aimed at limiting greenhouse gas emissions in developed countries to curb global warming was recognized and quickly implemented by 39 OECD countries. The protocol provided specific emission reduction targets for six greenhouse gases such as carbon dioxide. In the period from 2008 to 2012, the level of greenhouse gas emissions in these signatories was required to reduce by $5.2 \%$, among which the United States was required to reduce by 7\%, the EU 8\%, Japan 6\%, Canada $6 \%$, and Eastern Europe 5\% - 8\%. If any country cannot complete the emission reduction commitments, it will be subject to relevant economic sanctions. This protocol fully reflects that the international community has put high attention and made unremitting efforts on global warming.

China is the largest emitter of carbon dioxide in the world. According to some relevant data, the total global emissions are 357 tons in 2014 and the top 6 emissions are China, the United States, the European Union, India, Russia and Japan, accounting for $69.2 \%$ of the world. It is worth noting that China alone has as much as 105 tons of carbon emissions, which is the only country whose carbon emissions are more than 100 tons. At present, China is in the stage of rapid urbanization and industrialization, which is characterized by high energy consumption, high emission and extensive economic growth. With the rapid economic growth, the inefficient exploitation and excessive consumption of resources have led to a series of problems of resources and environment, which has become the main problem that restricts the economic and social development of our country. In recent years, with the transformation of Chinese economy from the extensive economy of high energy consumption and high pollution to low energy consumption, environmentally-friendly economy, how to improve the market mechanism oriented tax policy to improve energy efficiency and reduce carbon emissions has become an important issue that the Chinese economy faces while maintaining sustained economic growth. In order to maintain a good balance between economic development and environmental pollution, resource tax is proposed as an important means of regulating resource consumption and economic development. In 1993, the State Council revised and promulgated the Interim Regulations on resource tax, in which the range of resource tax levied was expanded to 7 kinds, taking "the general collection, differential regulation" from the amount on volume method. Since then, China raised the resource tax rate many times. In 2010 China implemented the oil and gas resources tax reform pilot and the way of tax levied change from the amount on volume method to ad valorem method at the rate of 5\%. Since December 1, 2010, the reform has been extended to 12 provinces in the western region. In September 30, 2011, the revised "Provisional Regulations on resource tax" officially released and was implemented nationwide from November 1, 2011. At present, the resource tax reform has achieved significant results in promoting energy-saving emission reduction. As shown in Figure 1, with the increase of resource tax in the proportion of the total national tax revenue since 2002, the $\mathrm{CO}_{2}$ emissions per unit of GDP decreased year by year. 


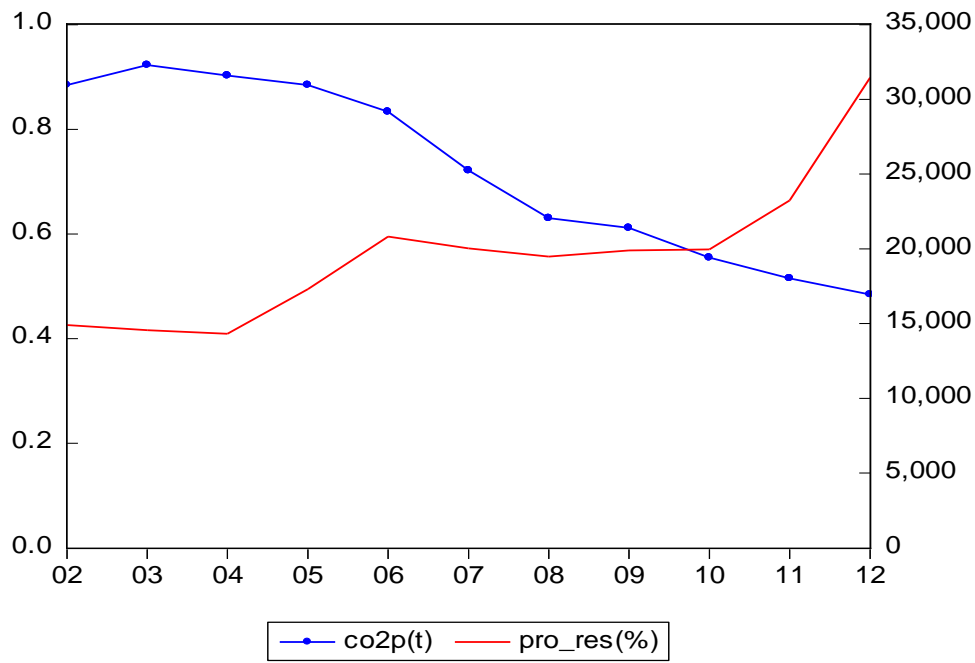

Figure 1. The proportion of resource tax in the total tax revenue and the trend of $\mathrm{CO}_{2}$ emissions per unit of GDP in 2002-2012.

\section{Literature Review}

The famous British economist Pigou (1920) [1] firstly proposed that the government can levy taxes on people according to the degree of pollution in his book "The economics of welfare" to balance the gap between private cost and social cost by taxation and internalize the externality of environmental pollution. The Pigou tax system provides a theoretical basis for the study of carbon emission reduction related tax policies. Since that the implementation of resource tax in China is not long, Domestic scholars mainly focus on the research of foreign carbon emission reduction tax policy as well as carry out the theoretical analysis and hypothesis analysis about which is more suitable for China's current national conditions, the carbon emission reduction policy tools-based on the price mechanism of resource tax or emission control based on the total amount of emissions trading. For example, Liu Xiaochuan, Wang Cengtao (2009) [2] considered that the emission reduction effect of carbon tax is limited and emission reduction should be based on the emission trading in the current condition that energy prices are led by the government. After the energy price market mechanism has been improved, it has gradually changed to consider the carbon tax as the theme of the emission reduction policy system. Li Botao (2012) [3] thought that carbon tax and emissions trading both have their own advantages and disadvantages, the key is how to design a reasonable strategy. Most of the above studies focus on theoretical analysis, but the existing literature on the analysis of the effect of the current tax policy on carbon emissions is rare. Among them, the quantitative analysis of carbon emission reduction effect of different environmental policies and its impact on the macroeconomic of the general equilibrium (CGE) model has been widely used in this field. Howarth, Winslow(1994) [4] considered that the carbon tax will internalize the external costs of climate change in the partial equilibrium analysis, thus the price increases, the energy consumption decreases, and the carbon dioxide emissions decrease under the new equilibrium condition. The government can reduce carbon dioxide emissions by collecting carbon tax, which is conducive to the realization of low-carbon economy. Xu Xiaoliang (2012) [5] 
found that there is a great difference between the influence of the design of resource tax policy on the output of related industry and the change of the industrial structure of different regions by constructing a dynamic multi zone CGE model and that the establishment of resource tax rate plays a positive role in adjusting the industrial structure and narrowing regional differences. The higher the resource tax rate is, the higher the efficiency of resource utilization is and the better the effect of emission reduction is. Yao Xin, Liu Xiying (2010) [6] found that the introduction of carbon tax is not only conducive to reduce carbon emissions and improve energy efficiency, but also can it effectively adjust the industrial structure by solving the optimal carbon tax CGE model based on welfare maximization. Due to the dynamic CGE simulation analysis method is based on top-down analysis of the total carbon tax policy without consideration of energy production and use of technical details in the process, Most of the literature in which the technical progress is adopted cannot truly reflect the effect of technology spillover effect on the abatement cost and the uncertainty of the discount rate in the model, technological change and economic subject behavior assumption, closed rule selection and parameter setting and other factors can lead to a great impact on the simulation results. In the field of quantitative analysis, some scholars have explained the effect of resource tax on energy conservation and emission reduction from the perspective of the influence of resource tax on mineral resources industry. For example, Luo Nengsheng, etc. (2013) [7] constructed the multi factor dynamic panel model of 2001-2010 based on Cobb Douglas production function and used the generalized matrix method to test the long-term effects of resource tax adjustment on mineral resources industry. The results show that the adjustment of resource tax can optimize the organization structure of production factors and improve production efficiency. As far as the regional effect is concerned, the effect of resource tax on the central and western regions is stronger than that in the east. The above research mainly studies the impact of resource tax on mineral resources industry from the whole and ignores the difference of resource tax on the consumption of different resources.

In view of the present situation of China's resource tax reform and the shortcomings of the current research, this paper analyzes the effect of resource tax on carbon emission reduction from the perspective of the impact of resource tax policy on the structure of production factors in the resource consumption industry. This paper takes into account the differences in the structure of the factors affecting the structure of resource tax and divided the industry into high-energy industry and low-energy industry, resource production industry and non-resource production industry to analysis of the impact of adjustment of resource tax on the energy input and structure of industry in different industries. Then this paper will reveals the influence of resource tax adjustment on carbon emission reduction and puts forward relevant policy suggestions.

\section{Mechanism Analysis of the Effect of Resource Tax on Carbon Emissions}

Carbon emissions are the general name of greenhouse gas emissions, because carbon dioxide is the main component of greenhouse gases, we usually refer to as carbon emissions refers to carbon dioxide emissions. The burning of fossil fuels is the main cause of 
carbon dioxide. Therefore, the most direct way to reduce carbon emissions is to reduce energy consumption in industrial production. In order to understand the transfer of resource tax burden, we might as well consider the process of resource exploitation, processing and consumption as an industrial chain. First of all, the upstream industry chain composed of resource production enterprises is responsible for the exploitation of resources and the processing of resources and sells them to the users of resources products. The downstream industries composed of the resource consuming enterprises carry out the production of the products with various kinds of resources as the factors of production and sell the final products to the end consumers of the industrial chain [8]. We can get the transfer path of the resource tax from the transmission path of the industrial chain, of course, the way and degree of the transfer of the resource tax burden can also be impacted by market structure and demand elasticity (Figure 2).

In the fully competitive market conditions, when the resource tax rate increases, the price of related resources will rise. It is assumed that the factors of production can be replaced, and the production function consisting of three elements of capital, labor and energy is $\mathrm{Y}=\mathrm{f}(\mathrm{K}, \mathrm{L}, \mathrm{E})$, correspondingly, the cost function can be expressed as $\mathrm{C}=\mathrm{g}$ $\left(\mathrm{Y}, \mathrm{P}_{\mathrm{K}}, \mathrm{P}_{\mathrm{L}}, \mathrm{P}_{\mathrm{E}}\right), \mathrm{P}_{\mathrm{K}}$ represents the price of capital, $\mathrm{P}_{\mathrm{L}}$ represents the price of labor and $\mathrm{P}_{\mathrm{E}}$ represents the price of energy. In order to study the relationship between energy factors and other non energy factors, we choose transcendental logarithmic cost function. Specific form is:

$$
\begin{aligned}
\ln C= & \alpha_{0}+\alpha_{Y} \ln Y+\frac{1}{2} \alpha_{Y Y}(\ln Y)^{2}+\sum_{i=1}^{3} \alpha_{i} \ln P_{i} \\
& +\frac{1}{2} \sum_{i=1}^{3} \sum_{j=1}^{3} \alpha_{i j} \ln P_{i} \ln P_{j}+\beta_{T} T+\frac{1}{2} \beta_{T T} T^{2}(i, j=K, L, E)
\end{aligned}
$$

$\alpha_{0}$ represents the cost share independent of the price of the input element; $\alpha_{i}=$ $\partial \ln C / \partial \ln P_{i}$ represents the effect of price of production factor changes on total cost; $\alpha_{i j}=$ $\partial^{2} \ln C / \ln P_{i} \cdot \ln P_{j}$ is substitution parameter which is used to measure the change of the cost share with the price changes of the factors of production. Since the cost function is a homogeneous function of the price, the following conditions are met:

$$
\sum_{\mathrm{i}=1}^{3} \alpha_{i}=1 \quad \sum_{j=1}^{3} \alpha_{i j}=0 \quad \alpha_{i j}=\alpha_{j i}
$$

The first order derivative of the transcendental logarithmic cost function:

$$
\partial \ln C / \partial \ln P_{i}=\frac{\partial C}{\partial P_{i}} \frac{P_{i}}{C}=\alpha_{i}+\sum_{j} \alpha_{i j} \ln P_{j}
$$

Assuming that the factor market is perfectly competitive and the price of the input factor is fixed and at a given output level, we determine the demand of the elements

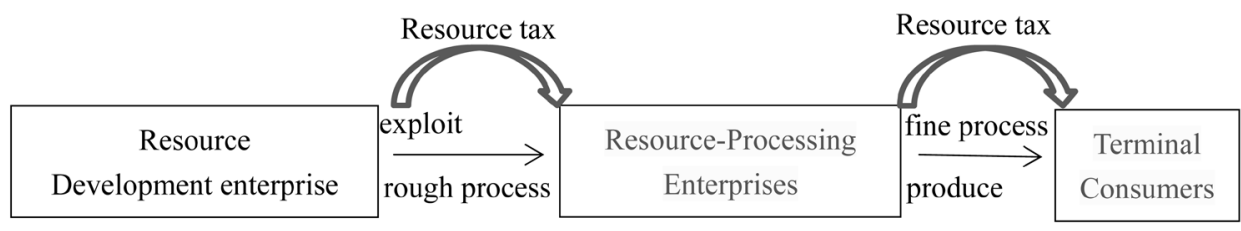

Figure 2. Process chart of resource exploitation, processing and consumption and transfer path of resource tax. 
under the constraint of minimizing the cost. According to Shepard's lemma, we get the derivative of the price and get the factor demand function:

$$
\mathrm{x}_{i}=\partial C / \partial P_{\mathrm{i}}, i=K, E, L
$$

The type of substitution (2) (3) obtained input demand equations of share:

$$
\mathrm{s}_{i}=x_{i} P_{i} / C=\alpha_{i}+\sum_{j} \alpha_{i j} \ln P_{j}
$$

The price elasticity of factor demand between $X_{i}$ and $X_{j}$ is:

$$
\varphi_{i j}=\frac{\alpha_{i j}+s_{i} s_{j}}{s_{i}}(i \neq j), \varphi_{\mathrm{i} i}=\frac{\alpha_{i i}+s_{i}\left(s_{i}-1\right)}{s_{i}}
$$

$\varphi_{i j}$ represents the percentage of change in the demand of factor I when the $\mathrm{j}$ factor price changes by $1 \%, \varphi_{i i}$ represents the percentage change in the demand of I when the price of itself changes. Here we assume that there is an alternative relationship between capital, labor and energy and do not consider the relationship between the various sources of energy, so $\varphi_{i i}<0, \varphi_{i j}>0$. When the price of other factors is constant and the price of energy factors rises, the relative price between energy and non-energy factors will increase. As a result, the demand for energy sources will be reduced, while the demand for capital and labor will increase. The price elasticity of demand between factors indicates the degree of influence of the change of one factor price on other factors, which can be seen from the Formula (4), which depends on the size of the three variables $\alpha_{i j}$, $s_{i}$, $s_{j}$. We can discuss them separately: 1) $\alpha_{i j}$ represents the impact of price changes on the cost share. If the price change of one factor has a greater impact on the cost share, the demand for other factors will change when the factor price increases. 2) $s_{i}$ represents the proportion of alternative factors in the total cost. The greater the proportion is, the smaller the price elasticity of demand will be; $s_{j}$ represents the share of the total cost of energy. The greater this figure is, the greater the price elasticity of demand will be. If there is an alternative relationship between the factors of production in the resource consumption industry, The government can increase the cost of resources in production by increasing the resource tax rate and replace energy elements using non-energy elements through the price mechanism so as to achieve the role of energy saving and emission reduction. At the same time, because of the substitution of nonenergy factors to energy elements, it is helpful to optimize the structure of production factors, which will also play a positive role in promoting the efficiency of the resource consumption industry.

\section{An Empirical Study on the Influence of Resource Tax on the Structure of Industrial Sectors}

\subsection{Measurement Model Setting}

In 1830s, American mathematician C. W. Cobb and economic scientist Paul H. Douglas (1928) [9] proposed the famous Cobb-Douglas production function, which can be expressed as $Y=A(t) K^{\alpha} L^{\beta} \mu . A(t)$ represents technical level, K represents capital, $\mathrm{L}$ represents labor, $\alpha$ is output elasticity of capital; $\beta$ is output elasticity of labor; $\mu$ reflect the influence of random disturbance and $\mu \leq 1$. Because this paper studies the impact of resource tax on the structure of the industry, we add a variable to reflect the resource 
tax. Shao Rong Li (2005) [10] introduced the tax factor into the production function and thought that energy was a factor of production. Then Cobb Douglas production function model including resource tax is proposed:

$$
Y=K^{\sum_{\mathrm{i}=1}^{n} \alpha_{i} \xi_{i}} L^{\sum_{\mathrm{i}=1}^{n} \beta_{i} \xi_{i}} E^{\sum_{\mathrm{i}=1}^{n} \gamma_{i} \xi_{i}} \mathrm{e}^{\sum_{\mathrm{i}=1}^{n} c+\mu \xi_{t} R_{t}+\varepsilon_{t}}
$$

In this formula, $Y, K, L, E$ respectively represent the total output, capital input, labor input and energy consumption; $\xi_{i}$ represents the share of total tax revenue of category $\mathrm{i}$ taxes; $R$ represents total tax. This paper only considers the single tax, that is, the impact of resource tax on the structure of the production factors rather than the influence of the influence of China's overall tax structure on the structure of production factors. Therefore, the production function is simplified and a new production function is obtained:

$$
Y_{i t}=K_{i t}^{\alpha \xi_{t}} L_{i t}^{\beta \xi_{t}} E_{i t}^{\gamma \xi_{t}} e^{c+\mu \xi_{t} R_{t}+\varepsilon_{t}}
$$

Evaluating the logarithm of both ends of the above formula, we can get the econometric model to measure the effect of resource tax on the efficiency of production factors:

$$
\ln Y_{i t}=C+\alpha \xi_{i t} \ln K_{i t}+\beta \xi_{i t} \ln L_{i t}+\gamma \ln E_{i t}+\mu \xi_{i t} R_{i t}+\varepsilon_{i t}
$$

In the expression $i$ and $t$ represent industry and year, respectively, $\varepsilon_{i t}$ is error term, $\alpha$, $\beta$ and $\gamma$ separately indicate that the influence of the share of the resource tax revenue to the total tax revenue on the output elasticity of capital input, the output elasticity of labor input and the input output elasticity of the energy input and they can also be used to indicate the effect of resource tax share on the productivity of capital, labor and energy; $\mu$ represents the effect of the change of the resource tax revenue on the scale of economic production in the case of capital factor, labor factor and energy factor unchanged and excluding the impact of capital, labor and energy factor. If $\mu$ is positive, it said that the scale of economic production will expand with the increase in resource tax revenue. Then the combination of capital, labor and energy elements is an effective combination of the allocation of factors of production and the increase of resource tax is conducive to economic growth; if $\mu$ is negative, it said that the combination of capital, labor and energy consumption factors of production scale is inefficient and the increase in resource tax revenue inhibits economic growth. It should be noted that China began to reform the resource tax and increase unit tax on resource tax many times since 1990. However, due to the different unit tax on resource tax in different regions and Xinjiang has become a pilot reform of oil and gas resources tax using the method of an ad valorem collection since 2009, taxing from the amount of taxable and ad valorem co-existed in China. Therefore, looking from the resource tax reform process, the implementation of the resource tax reform not only has the difference in the different resources, but also has the difference in the time and in the study area. It is very difficult for us to select an index to direct representation of the resource tax reform. Based on the method of Luo Nengsheng (2013) [7], this paper used the resource tax share of total tax to reflect the reform of resource tax. Regardless of resource tax reform measures, it is shown as an increase in the share of resource tax in the total amount of tax revenue. 


\subsection{Data Description}

In order to test the effect of the increase of the proportion of the resource tax on the structure of the production factors in the industry, and then explore the impact on the carbon emissions, we firstly establish a panel data model of the relevant data of 2003-2011 from coal mining and coal washing industry, oil and gas industry and other 39 industries according to industry classification. Dependent variable $Y_{i t}$ represents the industrial output value (100 million yuan) of the i industry in the $t$ year; independent variable $K_{i t}, L_{i t} E_{i t}, \xi_{i t}, R_{i t}$ respectively refers to Total value of fixed assets (100 million yuan), average number of employed persons (10,000 persons), total energy consumption (10000 $\mathrm{t}$ standard coal), resource tax accounted for the proportion of total tax revenue (\%) and total tax (100 million yuan) of the $i$ industry in the $t$ year. The relevant data in this paper are from 2004 to 2012, "China Statistical Yearbook", "China Industrial Economic Statistical Yearbook" and "China energy statistical yearbook". In order to eliminate the impact of price factors, this paper dealt with the data of the total industrial output value and total fixed assets value based on year 2003 by using the producer price index and fixed assets investment price index of each industry by year. It should be noted that the producer price index of extractive industry is taken as an alternative due to the lack of producer price index data for other mining producers in this paper. In order to eliminate the variance of each index and the disturbance of the possible strong influence point to the estimated value of the model, the logarithm of the collected data is processed. Due to resource tax effect energy demand in production through the price mechanism, the impact of resource tax on the demand of production factors in different industries is different because of different levels of energy consumption. Therefore, this paper divides the industry into high energy consuming and low energy consuming industries respectively to conduct a regression analysis. The high energy consumption industry refers to the six high energy consuming industries specified in "the national economic and social development statistical report in 2010", including chemical raw materials and chemical products manufacturing, non-metallic mineral products industry, ferrous metal smelting and rolling processing industry, non-ferrous metal smelting and rolling processing industry, oil processing and coking and nuclear fuel processing industry, electricity and heat production and supply industry.

\subsection{Empirical Results and Interpretations}

From the estimation results of Table 1, we can find that coefficient of resource tax revenue as an explanatory variable is $\mu=0.0016$ and the variable passed $1 \%$ significant test, which shows that the increase of the proportion of the resource tax can enlarge the scale of related industries to a certain extent. As a result of the substitution of the factors of production and the improvement of the efficiency of energy using, it can reduce the negative impact on the output due to the increase of the cost of consumption of resources and the reduction of energy input. It will not only adversely affect the size of the economy as a whole, but also accelerate the development of the industry. Known by $\alpha=0.69, \beta=0.35$, the increase of the proportion of the resource tax will increase the contribution rate of capital and labor input to the output, so that the enterprise will in- 
Table 1. Estimation of industrial production function model.

\begin{tabular}{cccccc}
\hline variable & $\begin{array}{c}\text { All of the } \\
\text { industry }\end{array}$ & $\begin{array}{c}\text { High-energy } \\
\text { industry }\end{array}$ & $\begin{array}{c}\text { Low-energy } \\
\text { industry }\end{array}$ & $\begin{array}{c}\text { Resource } \\
\text { production } \\
\text { industry }\end{array}$ & $\begin{array}{c}\text { Non-resource } \\
\text { production } \\
\text { industry }\end{array}$ \\
\hline res_lninv & $0.687^{* * *}$ & $0.911^{* * *}$ & $0.700^{* * *}$ & 0.0214 & $1.171^{* * *}$ \\
res_lnlabor & $(0.115)$ & $(0.327)$ & $(0.123)$ & $(0.301)$ & $(0.124)$ \\
res_lnene & $0.346^{* * *}$ & $2.045^{* * *}$ & $0.328^{* * *}$ & $0.655^{* *}$ & $0.410^{* * *}$ \\
res_tax & $(0.113)$ & $(0.482)$ & $(0.123)$ & $(0.318)$ & $(0.122)$ \\
& $-0.662^{* * *}$ & $-1.689^{* * *}$ & $-0.686^{* * *}$ & -0.255 & $-1.145^{* * *}$ \\
Constant & $(0.0755)$ & $(0.361)$ & $(0.0841)$ & $(0.174)$ & $(0.0926)$ \\
& $0.00161^{* * *}$ & $0.00102^{* * *}$ & $0.00168^{* * *}$ & $0.00220^{* * *}$ & $0.00116^{* * *}$ \\
& $(0.000158)$ & $(0.000364)$ & $(0.000178)$ & $(0.000609)$ & $(0.000153)$ \\
Observations & $6.959^{* * *}$ & $7.946^{* * *}$ & $6.770^{* * *}$ & $5.729^{* * *}$ & $7.082^{* * *}$ \\
R-squared & $(0.0974)$ & $(0.219)$ & $(0.111)$ & $(0.355)$ & $(0.0906)$ \\
Number of industry & 351 & 54 & 297 & 54 & 297 \\
\hline
\end{tabular}

Standard errors in parentheses. ${ }^{* *} p<0.01,{ }^{* *} p<0.05,{ }^{*} p<0.1$.

crease the share of capital and labor in the process of production. while $\gamma$ is -0.66 , it can be seen that the increase of the proportion of the resource tax will inhibit the contribution of energy input to the output, so that the enterprise will reduce the energy input in the production process. Therefore, from the perspective of influence on the production efficiency of production factors from resource tax, if the proportion of resource tax increases, the cost of the use of resources will increase. Then the other non-energy elements will instead of the energy factor and enterprises will choose a more cost-effective way to organize production to increase capital and labor in the production. Of course, to compare the coefficient of capital and labor, the effect of resource tax on capital productivity is more significant than that of labor productivity. The instead of non-energy elements to energy factors means to reduce energy consumption in industrial production and carbon emissions per unit of GDP will be reduced accordingly, thus the resource tax does not affect the output, according to industry production factor structure plays a role of energy conservation.

\subsubsection{High-Energy Industries vs Low-Energy Industries}

Since resource tax impact on energy demand in production through price mechanism, the influence of resource tax on the demand of production factors is different from the different level of energy consumption in different industries. Therefore, this paper will be divided into high-energy industry and low-energy industries to conduct regression analysis. The high-energy industry refers to the six high energy consuming industries in the national economic and social development statistical report in 2010. They are chemical raw materials and chemical products manufacturing, non-metallic mineral products industry, ferrous metal smelting and rolling processing industry, non-ferrous metal smelting and rolling processing industry, oil processing and coking and nuclear 
fuel processing industry, electricity and heat production and supply industry. From the empirical results, the output elasticity of resource tax share on capital and labor force input is positive for high energy consuming industries and low energy consuming industries, which points out that the increase of the share of the resource tax will be beneficial to the rationalization of the organization of the internal factors of production. Specifically, when the resource tax accounted for the total share of tax increases, rational decision-makers will choose to increase capital investment and human resources to organize production because it has significant effect on capital and labor productivity. According to the results of the model, the $\gamma$ of high-energy consuming industries and low-energy consuming industries are -1.69 and -0.69 . It shows that whether in the industries of high energy consumption or low energy consumption, the increase of resource tax accounted for the total proportion of tax will inhibit the energy factor's contribution to the output and the enterprise will reduce energy inputs in production so that the labor and capital have the substitution effect on the energy factor. In the case of the same general trend, we can easily find that the impact of resource tax on high energy consumption industry is significantly higher than the low energy industry. On this point we can explain from the factors of production price elasticity of demand. Price elasticity of demand among production factors is $\varphi_{i i}=\left(\alpha_{i j}+s_{i} \cdot s_{j}\right) / s_{i}$. When the resource tax rate increases, the resource price and the cost of energy increase. Since the cost of energy input in the high energy consuming industry is higher than that in the low energy consumption industry, we can draw that $s_{j}$ of high energy consuming industry is bigger than that of low energy consumption industry. Accordingly, the impact of rising energy prices on the demand for non-energy factors of high energy consuming industries is stronger than that of low energy consumption industries. In addition, the substitution effect of ca on energy factors is also different in these two categories. For the high energy consumption industry, the share of the resource tax in the total tax revenue is significantly stronger than the output elasticity of labor input while the low energy consumption industry is the opposite. On average, the technology level of highenergy consuming industry generally lags behind the low-energy consumption industry. If it wants to reduce the level of energy consumption in the short term, the most direct way is to introduce advanced technology and equipment. Therefore, the resource tax impact on the output elasticity of capital is bigger than that of labor. For some low-energy consumption industries, they can more effectively reduce the level of energy consumption through the introduction of high-quality talent approach due to the technical level has been at a high level.

\subsubsection{Resource Production Industry vs Non-Resource Production Industry}

The majority of industry belongs to resource consumption industries. Of course, there are also some industries, for example, coal mining and dressing industry, petroleum and natural gas mining industry, which are not only the resource consumption industry, but also the resource production industry. Then the impact of resource tax on such industries may also be different from other industries, so it is necessary to discuss the situation. From the empirical results, the impact of resource tax on resource production industry is not significant compared with non-resource based industries. Specifically, although the coefficient of variation of the share of resource tax on the output elasticity 
of capital factor inputs is positive, it cannot pass the significance test. On the one hand, since the resource production industry belongs to the low energy consumption industry, as mentioned earlier, the price elasticity of demand is lower than the high energy consumption industry and the increase in the proportion of resource tax has little effect on the demand for non-energy factors. On the other hand, from the perspective of the tax burden, when the resource tax rate increase, the tax burden is not completely transferred from resource production industry to resource consumption industries, in other words, the tax burden sharing between them. In this context, regardless of whether the consumption of resources, resource production industry will bear some burden. However, for resource consumption industry, if it does not consume resources, it will not need to bear the tax burden. Therefore, the impact of rising energy prices caused by the increase in resource tax on production costs is different for these two kinds of industries. The price elasticity of demand is $\varphi_{i i}=\left(\alpha_{i j}+s_{i n} \cdot s_{j}\right) / s_{i}$ and $\alpha_{i j}$ for resource production industry is less than $\alpha_{i j}$ for non-resource production industry, so the price elasticity of demand is less than the price elasticity of non-resource production industry. Based on the above two reasons, the influence of the increase of the proportion of the resource tax on the resource production industry is less than that of the non-resource production industry. From the comparison of the elasticity of substitution of capital and labor, resource production industry and non-resource production industries are different two. Since most of resource production industry belongs to the labor-intensive industries, the demand for labor is higher. Therefore, the output elasticity of labor coursed by resource tax increasing is bigger than that of capital and non-resource production industry is just the opposite.

\section{Conclusion}

By constructing and solving the industrial production function including energy factors, we can see that, the increase of resource tax can promote the enterprises to organize the production process more effectively and improve the production efficiency, and the increase in the cost of use of resources will enable companies to seek more efficient alternative elements and more reasonable production processes; in that way capital and human resources will be used more in the production process to ensure sustained growth in industrial output. Therefore, government regulation of resource tax can optimize the elements structure proportion in the production process to improve the energy consumption in the production efficiency of the industry. On the other hand, it can force the energy consumption industry to replace the energy elements by capital and human resources to reduce the energy input in the production process, thus achieving the goal of energy saving and emission reduction. At the same time, we can also find that the impact of resource tax on high energy consuming industries is higher than that of low energy consumption industries, and the impact on the non-resource production industries is higher than that of resource production industries. To sum up, the government should improve the resource tax rate as a means of energy conservation and emission reduction policy mainly for high energy consumption and non-resource production industry. 


\section{References}

[1] Pigou, A.C. (1920) The Economics of Welfare. Macmillan and Co., London.

[2] Liu, X.C. and Wang, Z.T. (2009) Comparison of Carbon Dioxide Emission Reduction Policies and China's Optimal Choice. Journal of Shanghai University of Finance and Economics, 4, 74-88.

[3] Li, B.T. (2012) The Debate on the Choice of Policy Tools for Carbon Pricing: A Literature Review. Economic Review, 2, 153-160.

[4] Howarth, R.B. and Winslow, M.A. (1994) Energy Use and $\mathrm{CO}_{2}$, Emissions Reduction: Integrating Pricing and Regulatory Policies. Energy, 19, 855-867. https://doi.org/10.1016/0360-5442(94)90038-8

[5] Xu, X.L. (2012) Resource Tax Reform Can Adjust Regional Differences and Energy Conservation and Emission Reduction? Analysis of Dynamic Multi Zone CGE Model. Economic Science, 5, 45-54.

[6] Yao, X. and Liu, X.Y. (2010) A Study on the Optimal Carbon Tax in China From the Perspective of Growth. Economic Research, 11, 49-60.

[7] Luo, N.S., Zhang, X. and Xiao, L.L. (2013) Long Term Effects of Resource Tax Reform on the Development of Mineral Resources Industry in China. Economic Geography, 12, 123129.

[8] Wang, M. (2015) The Effect of Resource Tax and Resource Tax Reform. Tax Research, 5, 54-59.

[9] Cobb, C.W. and Douglas, P.H. (1928) A Theory of Production. American Economic Review, 18, 139-165.

[10] Li, S.R. and Geng, Y. (2005) Tax Structure, Economic Growth and Income Distribution in China. Economic Research, 5, 118-126.

\section{Submit or recommend next manuscript to SCIRP and we will provide best service} for you:

Accepting pre-submission inquiries through Email, Facebook, LinkedIn, Twitter, etc. A wide selection of journals (inclusive of 9 subjects, more than 200 journals)

Providing 24-hour high-quality service

User-friendly online submission system

Fair and swift peer-review system

Efficient typesetting and proofreading procedure

Display of the result of downloads and visits, as well as the number of cited articles

Maximum dissemination of your research work

Submit your manuscript at: http://papersubmission.scirp.org/

Or contact ojbm@scirp.org 